\title{
ANALYTICAL STUDY ON EFFECTS OF WATER QUALITY PARAMETERS USING REMOTE SENSING \& GIS UNDER HYDERABAD URBAN AREA ZONE - V
}

\author{
Gogana Venkateswarlu ${ }^{1}$ \\ ${ }^{1}$ Associate Professor, Department of Civil Engineerin, Anurag Group of Institutions, JNTU Hyderabad, India
}

\begin{abstract}
Rapid urbanization and industrialization has led to unchecked proliferation of hazardous industries in and around Hyderabad, unchecked and unregulated distribution and management of urban resources especially green areas, water bodies and the combination of above aspects with large scale urban sprawl have all made Hyderabad an unmanaged polluting city. One of the major problems 'Water Pollution' is referred to the addition to water an excess of material that is harmful to humans, animals, or desirable aquatic life, or otherwise causes significant departures from the normal activities of various living communities, in or near bodies of water. The term water pollution refers to any type of aquatic contamination between two extremes: A highly enriched over productive biotic community such as river or lake with nutrients from sewer or fertilizer. Water bodies poisoned by toxic chemicals, which eliminate living organizing, exclude all forms of life.
\end{abstract}

Many steps are being taken to keep pollutants from reaching groundwater supplies. Manufacturers should use fewer toxic raw materials. Consumers have switched to phosphate-free detergents and other less polluting household products. Pollution control measures such as the Clean Water Act have also been a big part of the protection of drinking water supplies. Reutilization and Recycling of Waste: Various kinds of wastes like paper pulp, municipal and industrial effluents, sewage and thermal pollutants can be recycled to advantage. For example, urban waste could be recycled to generate cheaper fuel gas and electricity. Removal of Pollutants- The various physicochemical techniques used for removal of chemical biological or radiological pollutants have been adsorption, electro dialysis, ion exchange and reverse osmosis etc.

Keywords: Water Bodies, Water Pollution, Water Quality.

$* * *$

\section{INTRODUCTION}

Water pollution occurs when a body of water is adversely affected due to the addition of large amount of materials to the water. When it is unfit for its intended use, water is considered polluted. Two types of pollutants exist; point source and nonpoint source. Point sources of pollution occur when harmful substances are emitted directly into a body of water. The Exxon Valdez oil spill best illustrates point source water pollution. A nonpoint source delivers pollutants indirectly through environmental changes. An example of this type of water pollution is when fertilizer from a field is carried into a stream by rain, in the form of run-off which in turn affects aquatic life. The technology exists for point sources of pollution to be monitored and regulated, although political factors may complicate matters. Nonpoint sources are much more difficult to control. Pollution arising from nonpoint sources accounts for a majority of the contaminants and lakes.

Pollution is also caused when silt and other suspended solids, such as soil, wash off plowed fields, construction and logging sites, urban areas, and eroded river banks when it rains. Under natural conditions, lakes, rivers, and other water bodies undergo Eutrophication, an aging process that slowly fills in the water body with sediment and organic matter. When these sediments enter various bodies of water, fish respiration becomes impaired, plant productivity and water depth become reduced, and aquatic organisms and their environments become suffocated. Pollution in the form of organic material enters water ways in many different forms as sewage, as leaves and grass clippings, or as runoff from livestock feedlots and pastures. When natural bacteria and protozoan in the water break down this organic material, they began to use up the oxygen dissolved in the water. Many types of fish and bottom-dwelling animals cannot survive when levels of dissolved oxygen drop below two to five parts per million. When this occurs, it kills aquatic organisms in large numbers which leads to disruption in the food chain.

In the view of this we treated the Impact assessment of land use change on ground water quality using remote sensing \& GIS for zone $\mathrm{V}$ under municipal corporation Hyderabad, in the present work the effect of polluted and treated water on fish were carried out. 
Hence a scientific and systematic study is attempted to identify the groundwater conditions for the Hyderabad city and its surroundings. The study is also aimed at presenting the ground water quality in different areas of the city and also at exploring the ground water potential areas and ground water pollution zones in the study area. Such a study will be of immense value in the light of the need for urban planning for the immediate future.

As this study is carried out with the main objective of bringing out a comprehensive picture of the ground water conditions in the Hyderabad city and its surroundings besides studying the drinking water supply mechanism in the study area, the observations of the study will have great significance in urban planning and water resource management. The findings of the study will be helpful for the planners and administrators of the Hyderabad Municipal Corporation in Zone V in a variety of ways.

\section{HYDERABAD URBAN AREA}

Hyderabad is the fifth largest metropolis in India and the capital state of Andhra Pradesh, also known as city of Charminar. This historical city is founded in 16th century by the fifth Qutub Shahi ruler of Golconda, Mohammed Quli Qutub Shah and common people used to refer it as "Bhagyanagar". The princely state of Hyderabad merged with Indian Union in 1948. It became the capital city of A.P. in 1956. In 1978, Hyderabad district was split into urban and rural district.

Hyderabad city is situated on the banks of river Musi at $17^{\circ} 22^{\text {, }}$ $\mathrm{N}$ latitude and $70^{\circ} 22^{\circ} \mathrm{E}$ longitudes and is in an average of 1734 $\mathrm{ft}$. above mean sea level. Musi River is a part of history and heritage of Hyderabad city. It emerges from Anathagin hills about $90 \mathrm{~km}$ to the west of Hyderabad and flows through Vikarabad, Pargi, Chevella. Kalvakul, Palankul and Golconda Mandals and reaches Osmansagar Reservoir at Gandipet which was built in 1920 to conserve flood water. Once beautiful and plentiful river it has become a stinking drain due to rapid unplanned development of Hyderabad and discharge ot domestic sewage. The human transition to urban settlement began 600 years ago and is a continuing phenomena creating complex environmental problems. The basic factor that contributes to urban growth phenomena led economic system with emphasis on extraction, production and growth process that benefit the human species at the cost of other species. The urban growth is catalyzed by accelerated utilization of renewable and non-renewable resources in the surrounding areas.

We have begun to discern the beginning of environmental crisps as well entered into $21 \mathrm{~s}$ century. We are surrounded faced with curse of desertification, soil maladies, flood, drought, urban congestion, extinction and / or threat to flora, fauna and ubiquitous pollution of land, air, and water.

\subsection{Location and Regional Settings}

The city lies between $78^{\circ} 22^{\prime} 30$ and $78^{\circ} 32^{\prime} 30^{\prime}$ East Longitude and between $17^{\circ} 18^{\prime} 30$ and $17^{\circ} 28^{\prime} 30$ North latitude. The city is situated in the Krishna Basin and River Musi, which is a tributary of river Krishna, is passing through the city of Hyderabad and bifurcates the city as north and south Hyderabad. Out of the 1534 Sq. Km. of Hyderabad development authority area, the Municipal Corporation of Hyderabad (MCH) has $179 \mathrm{Sq}$. Km. Out of the $\mathrm{MCH}$ area Zone- V extends at $78^{\circ} 26.49^{\prime} \mathrm{W}$ latitude and $17^{\circ} 24.5^{\prime} \mathrm{N}$ longitude with a total area of $18.309 \mathrm{Sq} . \mathrm{Km}$ which is selected for the present investigations.

\subsection{Physical Feature}

The city stands on gray and pink granites as foundation material, which is suitable for building construction. The soils of Hyderabad are mainly brownish sandy, rocks like dolomites and quartz basalt associated with granites yield in general brownish sandy soil and where the dolomite is predominant. The Northern most bit of the cantonment area starts with a contour of 570m above Mean Sea Level (MSL) [240][250] gradually slopping down southwards unto the river Musi where the lowest contour reaches $450 \mathrm{~m}$ above MSL. The level again raises gradually with small higher moalds here and there towards the southern extremity of the city into a maximum of $570 \mathrm{~m}$ above MSL. It can also be said that the level gradually falls from west to east.

\subsection{Climate}

The climate of the city is fairly equitable. The analysis of the meteorological data of the past 50 years shows that the daily mean maximum temperature varies from a minimum of $11.6^{\circ} \mathrm{C}$ during the month of December to a maximum of $40.5^{\circ} \mathrm{C}$. Hyderabad gets its rainfall mainly from the southwest monsoon from the month of June to October, amounting to an average of $64.20 \mathrm{~cm}$ on an average. The total annual average rainfall is about $73.55 \mathrm{~cm}$. There are periodic local meteorological disturbances, which also occasionally bring some showers. The number of days during which the wind blows from the west is $23 \%$, followed by $7 \%$ from northwest. The high percentage of winds blowing from the west is prevalent during the months, June to August, the maximum being during the month of July. The mean wind speed is also maximum during the month of July at $16 \mathrm{kmp} / \mathrm{h}$ and is minimum during the month of December at $4.8 \mathrm{kmp} / \mathrm{h}$. Air pollution scavenging or pollutants reaching the soils from the air are more common in the monsoon months. Of late, citizens of Hyderabad are experiencing deviations from these patterns of climate, which seems to be a common factor for all metropolitan cities in the country. 


\subsection{Water Courses and Water Sheds}

Hyderabad is a city of glittering lakes. At present two major water bodies, Hussain Sagar and Mir Alam Tank are situate within the Municipal limits, in addition to a couple of smaller ones at Nallakunta, Jubilee Hills, Ramanthapur, and other places. Two other major lakes situated within the $\mathrm{MCH}-\mathrm{Mir}$ Jumla and Masab Tanks have dried up. In general linkage between the surface waters and ground water recharge is a well known fact. The Musi flows through an area occasionally subject to torrential rains. The worst of the flood occurred in Musi in 1908, after which the two reservoirs of Himayat Sagar and Osman Sagar were constructed at about $16 \mathrm{~km}$ west of Hyderabad to control floods.

\subsection{Hydrology}

The ground water levels of the city show considerable variations during the year with a depth of around 10 to $15 \mathrm{~m}$ below ground level in the summer months and depth of around 2 to $8 \mathrm{~m}$ during the monsoon months. The study area is covered by granite of Archean age, intruded at places by dolerite dykes; occurrence of quartz veins is also a common feature. Ground water occurs in weathered and fractured zones. The ground water movement and occurrence shows distinct variations in the hard rock areas. In the downstream of Musi River the water levels are relatively deep In the study area the ground water is drawn mostly from bore wells and very few from open wells.

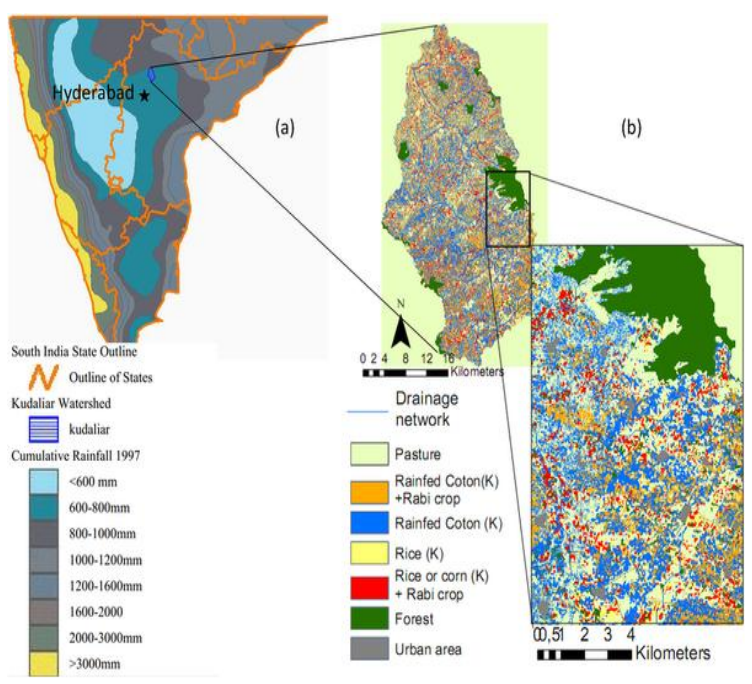

Fig -2.1: Map showing sampling points overlaid on satellite imagery of study area

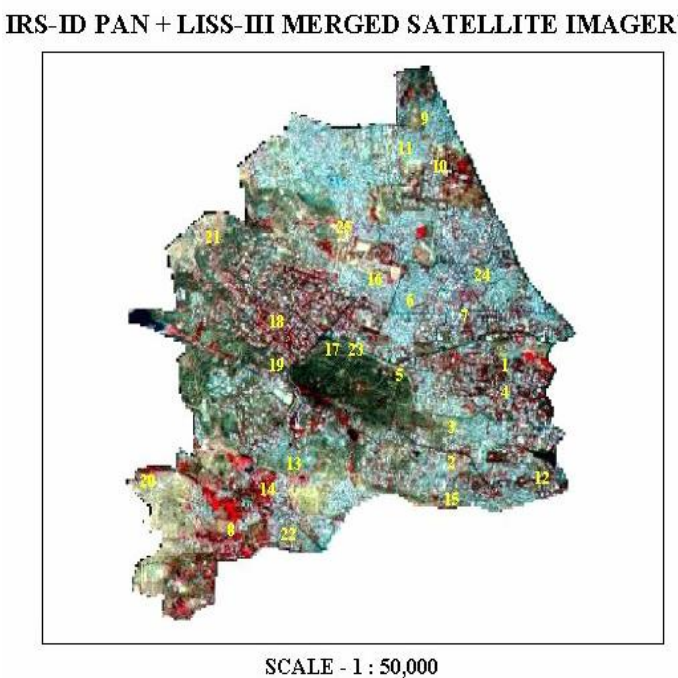

Fig -2.2: Sampling points overlaid on Satellite Imagery of Study area of Hyderabad South Zone circle - V

The above figure 2.2 explains about fieldwork was conducted and groundwater samples were collected from predetermined locations based on the land use change and drainage network maps of the study area. Map showing sampling points overlaid on satellite imagery as shown in Fig 1.4. The water samples were then analyzed for various physico-chemical parameters adopting standard protocols.

\subsection{Protection of Water Bodies}

Lakes, tanks, ponds and rivers come under this category. There are two water bodies present in the study area at Musi River and Hussain Sagar outlet that occupy an area of $0.42 \mathrm{sq}$ Kms. It is about 3\%. These water bodies are identified based on their tone, regular to irregular shape and smooth to mottled texture on the satellite imagery Surface water spread of the tank or lake varies from season to season. The major river present in the study area includes the Musi River. It appears as long, narrow to wide feature on the imagery with an irregular shape and a smooth texture. It is usually associated with vegetation along the banks and in the riverbed.

Hyderabad Deccan topography facilitated construction of a number of water storing devices (lakes, ponds, reservoirs etc...) both natural and manmade. They provided drinking water to millions and mainly helped in recharge of groundwater. So many of them have been disappeared and got seriously contaminated due to encroachments, land grabbing and discharge of untreated industrial effluents and domestic sewage. The attitude of the powers that has been that of apathy, connivance and collusion. This is a larger preference for costly water supply schemes rather than protecting the existing water bodies. 


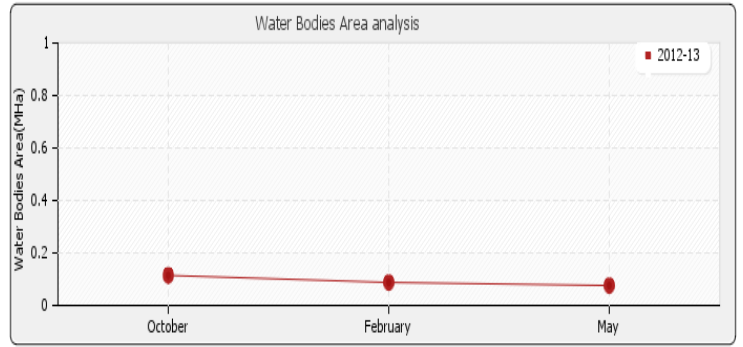

Fig -2.3: Map showing sampling points overlaid on satellite imagery of study area

\section{WATER POLLUTION}

Water pollution Fig 3.1 is referred to the addition to water of an excess of material that is harmful to humans, animals, or desirable aquatic life or otherwise causes significant departures from the normal activities of various liking communities, in or near water bodies.

Contamination can enter the water bodies through one or more of the following ways:

- Direct point sources: Transfer of Pollutants from municipal industrial liquid waste disposal sites and from municipal and household hazardous waste and refuse disposal sites.

- Diffuse agricultural sources: wash off and soil erosion from agricultural lands carrying materials applied during agricultural use, mainly fertilizers, herbicide and pesticides.

- Diffuse urban sources: Run off from city streets, from horticultural, gardening and commercial activities in the urban environment and from industrial sites and storage areas.

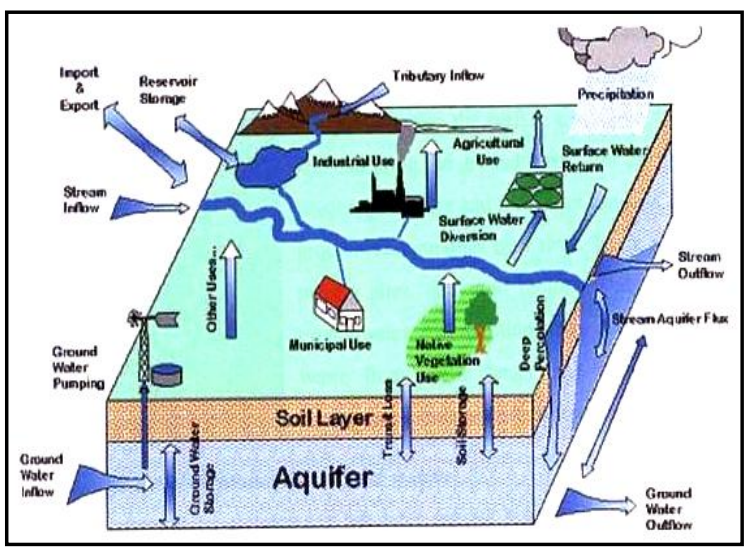

Fig -3.1: Water Pollution

A well can be easily contaminated if it is not properly constructed or if toxic materials are released into the well. Toxic material spilled or dumped near a well can leach into the aquifer and contaminate the groundwater drawn from that well. Contaminated wells used for drinking water are especially dangerous.

Pollutants that contaminate groundwater may be some of the same pollutants that contaminate surface water; compounds from the surface can move through the soil and end up in the groundwater. For example, domestic wastes, pesticides and fertilizers can find their way into groundwater supplies over time. Toxic substances from mining sites, and used motor oil also may seep into groundwater. In addition, it is possible for untreated waste from septic tanks and toxic chemicals from underground storage tanks to contaminate groundwater.

Drinking contaminated groundwater can have serious health effects. Diseases such as hepatitis and dysentery may be caused by contamination from septic tank waste. Poisoning may be caused by toxins that have leached into well water supplies. And it is important not to forget that wildlife, too, can be harmed by contaminated groundwater.

\subsection{Prevention and Control of Water Pollution}

Many steps are being taken to keep pollutants from reaching groundwater supplies. Manufacturers should use fewer toxic raw materials. Consumers have switched to phosphate-free detergents and other less polluting household products.

Pollution control measures such as the Clean Water Act have also been a big part of the protection of drinking water supplies. Mitigation measures are as follows:

- Stabilization of Ecosystem[117]: It is the most reliable way to control water pollution which involves reduction in waste input, harvesting and removal of biomass. trapping of nutrients, fish management and aeration.

- Reutilization and Recycling of Waste: Various kinds of wastes like paper pulp, municipal and industrial effluents, sewage and thermal pollutants can be recycled to advantage. For example, urban waste could be recycled to generate cheaper fuel gas and electricity.

- Removal of Pollutants: The various physicochemical techniques used for removal of chemical biological or radiological pollutants have been adsorption, electro dialysis, ion exchange and reverse osmosis etc.

\section{EFFECTS OF WATER QUALITY PARAMETERS ON HUMAN HEALTH AND DISTRIBUTION FOR VARIOUS USERS}

Any alteration in water quality due to natural reasons or due to anthropogenic reasons, will affect man, life forms and the domestic animals. Hence it is essential to ensure that the Chemical Constituents are within the prescribed limits in drinking water supplies. The effect of these substances 
depends on the quantity of water consumed per day and their concentration in the water.

Similarly quality of irrigation water for agricultural use should be in such a way that it does not impair plant growth or adversely affect the productivity of the land. The water quality for various uses should be as per specification of water required for particular use. The ground water samples collected at different sites in the study area were analyzed for various physico chemical parameters to determine the variations in the characteristics of ground water quality. The results obtained are given below:

a) $\mathbf{p H}: \mathrm{pH}$ is defined as the negative logarithm of hydrogen ion concentration present in water and is an indicator of the acidity or alkalinity of water) $\mathrm{pH}$ is determined with the help of a $\mathrm{pH}$ meter. The permissible value of $\mathrm{pH}$ recommended for public water supplies is in between 6.5 to 8.5 . The presence of mineral acids like sulphuric acid, iron, cadmium, aluminum (effluents) makes the water acidic i.e., $\mathrm{pH}=0-7$ and the presence of carbonates and bicarbonates of calcium, magnesium, potassium etc make the water alkaline i.e., $\mathrm{pH}=7-14$ the $\mathrm{pH}$ of water samples in the present area $\mathrm{pH}$ varied between 7.01 (Bhadurpur Nala (SW) to 8.28 (Mahaboob Gunj) most of the samples collected in study area showed neutral to slightly alkaline $\mathrm{pH}$.

- Effects: Corrosion of water mains is the main problem associated with acidic waters.

- Higher value of $\mathrm{pH}$ encourages the scale formation in water heating systems and also reduces the germicidal potential of chlorine.

- High $\mathrm{P}^{\mathrm{H}}$ induces the formation of trihalomethanes which are causing cancer in human beings.

b) Total Dissolved Solids: Dissolved minerals, gases and organic constituents may produce aesthetically displeasing colour, taste and odour. The mam source of TDS in ground water is the seepage of industrial and domestic wastes. The permissible value recommended for TDS is $500 \mathrm{mg} / 1$ as per Indian standard. The TDS concentration in the Present study area ranged from $285-1180 \mathrm{mg} / 1.56 \%$ of water samples collected showed high concentrations of TDS in areas like Kishanbagh, Ramanjpura, Afzal Gunj, Hussaini Alam, Gulab Singh Bowli, Asad Baba Nagar, Amberpet, Kamalanagar, Bazarghat, Bathkammakunta, Chikkadpally, Imlibun, Ghansi Bazar, Nawab Saheb Kunta High TDS concentrations in Bazarghat Kamalanagar (DW) etc., may be due to seepage of domestic wastes and insufficient rainfall. Samples collected nearby Musi River and outlet of Hussain Sagar at Chikkadpally showed high TDS concentration. Source: The impact of Residential area (Sewage disposal) Location of Slums along with Musi.
- Effects: Water with high solid content often has a laxative effect.

- Use of water with high amount of dissolved solids may lead to scaling in boilers, corrosion and degrade quality of product.

- The presence of high concentration of TDS depletes dissolved oxygen and causes displeasing dour, taste and colour. High concentrations of $3000 \mathrm{mg} / \mathrm{l}$ may also produce distress to livestock.

c) Hardness: Hardness of water is a measure of its capacity to form precipitates with soap and scales with certain anions present in the water. Temporary hardness also called carbonate hardness caused by carbonates and bicarbonates of calcium and magnesium is removed by boiling or adding some to water. Permanent hardness or non-carbonate hardness is due to presence of sulfates, chlorides and nitrates of calcium and magnesium. It can be removed only by Ion exchange or Zeolite process. The desirable limit of Hardness in water is $300 \mathrm{mg} / 1$. Areas like Nizam Colony, Chandulal Baradari, Maharaj Gunj, Darga etc. Showed hardness concentration greater than $300 \mathrm{mg} / 1$, which can be considered as very hard water with maximum value of $710 \mathrm{mg} / 1$ in highly residential area Nizam Colony.

- Effects: The precipitate formed by soap and hardness adheres to surface of tubs, sinks and utensils and stains clothes and dishes.

- The precipitate if remains in the pores, skin may feel rough and uncomfortable and may lose its texture.

- Increases cardio vascular diseases.

- Absolute soft waters are tasteless and effect the human cardiovascular system and cause heart attacks.

- Not suitable for production of ice, soft drink and textiles.

d) Fluoride: Fluoride of water is important in determining the suitability of water for drinking purpose use. Water in contact with natural deposits of fluoride such as fluorspar, calcium fluoride, cryolite and water contaminated with industrial effluents are found to contain excess fluorides. Fluorides can be categorized as: Fluorides are determined using ion selective electrode method. The fluoride concentration in the present study areas ranges from$0.45 \mathrm{mg} / 1$ - $5.83 \mathrm{mg} / 1$ in areas like Miralam Tank, Fathedarwaja, Bahadurpura, Kachiguda, Patelnagar and with a maximum value of $5.83 \mathrm{mg} / 1$ in dense residential area Golnaka. However for the studies a required to establish the linkages.

- Effects: Fluoride more than $1.5 \mathrm{mg} / 1$ it leads to discoloration of teeth called "Mottling ${ }^{11}$. The white patches formed later become yellow and turn brown or black 
- Fluoride in excess of $5 \mathrm{mg} / 1$ cause bone Flourosis and skeletal abnormalities. Fluoride less than 1 $\mathrm{mg} / 1$ cause dental cavities.

e) Sulfate: Sulfate is a naturally occurring cation ( $\mathrm{SO} 4)$ found in all kinds of natural waters discharge of industrial waste and domestic sewage in water tends to increase sulfate concentration most of them originate from the oxidation of sulphate ores, the presence of shales etc. Sulphate can be readily leached from zone of weathering by infiltrating waters and surface runoff. The desirable limit of sulphate concentration is $250 \mathrm{mg} / 1$ in waters intended for human consumption. Sulfates are determined spectro photometrically at wavelength of $420 \mathrm{~mm}$. The sulfate concentrations in the ground water samples of study area range from $8.5-120 \mathrm{mgl}$ indicating that the concentrations are well within the permissible limits as given by Indian standards.

Effects: Sulfate acts a purgative in adults and causes temporary diarrhoea and disorders of alimentary tract.

f) Alkalinity: Alkalinity is a measure of water to neutralize acids it is a measure of the quantity of ions that will react to neutralize $\mathrm{H}+$ ions. It's mainly caused due to bicarbonate, carbonate and hydroxyl ions. The permissible value of alkalinity as recommended by the Indian standards is $250 \mathrm{mg} / 1$ as $\mathrm{CaCo3}$. The alkalinity concentrations of the water samples collected in the present study area ranged from $17-690 \mathrm{mg} / 1$ as $\mathrm{CaCo}$.

- Effects: Highly alkaline waters are usually unpalatable. Alkalinity reacts with cat ions of water and forms precipitate which damages the people and appurtenances like value.

- Excess alkalinity gives a bitter taste to water. Excess alkalinity in water is harmful for irrigation, which leads to soil damage and reduce crop yields.

g) Chloride: Chloride is estimated by Argentometric method (Titrimetry) using silver nitrate as titrant and dichromate as indicator. Sodium chloride is the main substances responsible for chloride concentration in water. $250 \mathrm{mg} / 1$ being the desirable limit for chlorides, concentration greater impart a salty taste to water and is therefore objectionable.

- Effects: Excess chlorides in water cause cardio vascular diseases and imparts permanent hardness to water.

- Sands containing high chloride content are not preferred for use in sand blasting and construction.

- The recommended standard of sodium in drinking waters is $200 \mathrm{mg} / 1$. Source: Main Intrusion of $\mathrm{Cl}$ into ground water is through domestic sewage. h) Sodium: Sodium content of water samples is measured by flame photometer, which is based on principle of emission spectroscopy. The Sodium concentrations was found to be in the range of 17 to $200 \mathrm{mg} / 1$ in the present study indicating that it is within permissible limit, whereas the sample collected at Kamalanagar (DW)showed a Sodium concentration of $220 \mathrm{mg} / 1$.

- Effects: Presence of Sodium in high concentrations gives better taste to water

- Dangerous for Heart and Kidney patients.

- Corrosive to Metals.

- Toxic to Plants.

i) Potassium: The major natural source of potassium in ground water is feldspar, some micas and clay minerals. The concentration of potassium in the ground water samples of the present study area ranged from $2-76 \mathrm{mg} / 1$ potassium is determined using flame photometer which is based on the principle of emission spectroscopy. All the ground water samples in the present study area ranged in between permissible limits i.e., $200 \mathrm{mg} / \mathrm{l}$.

j) Phosphorous: Contamination of ground water by phosphorous is not a major problem unless the ground water constituents significantly move to surface water constituents significantly move to surface water flow from a watershed. The major environmental problem caused by high phosphorous concentration is eutrophication, which occurs only in surface waters rather than ground water, the phosphorous concentration was very low in the present case ranging from $0.004-2.5$.

k) Nitrate: Nitrate determinations are important to assess the self-purification properties of the water bodies and nutrient balance in surface waters and soil and state of decomposition of organic matter present in wastewater. Nitrates by sewage and other wastes rich in nitrates may contaminate surface water, nitrates were analyzed by UV method spectrophoto metrically at $220 \mathrm{~nm}$.

- Effects: Excess nitrate concentrations cause blue baby disease in infants and stimulate the algal aquatic growth.

- The nitrate concentrations of the zone ranged from $5.2 \mathrm{mg} / \mathrm{l}$ (Ramkote) - $140 \mathrm{mg} / 1$ (Bathkammakunta). 

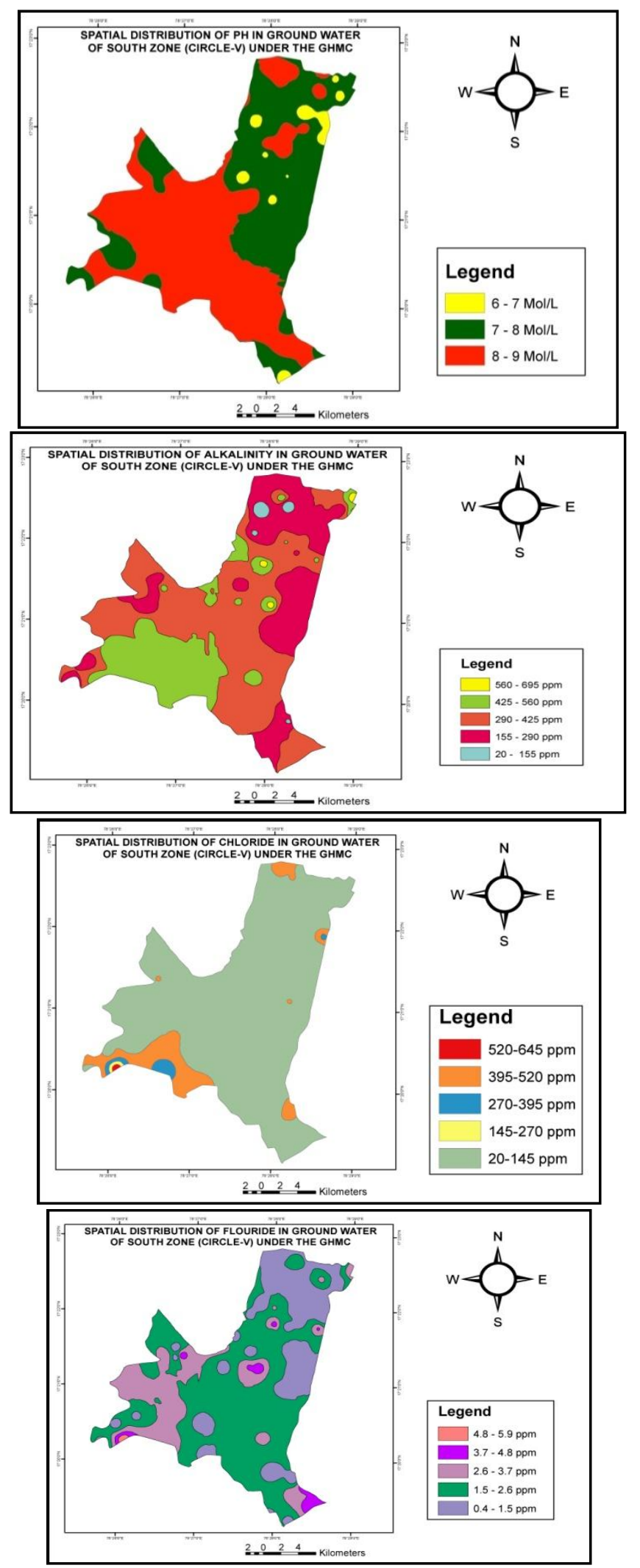

Fig -4.1: Effects of water quality parameters of $\mathrm{p}^{\mathrm{H}}$, Alkalinity, Chloride, Flouride
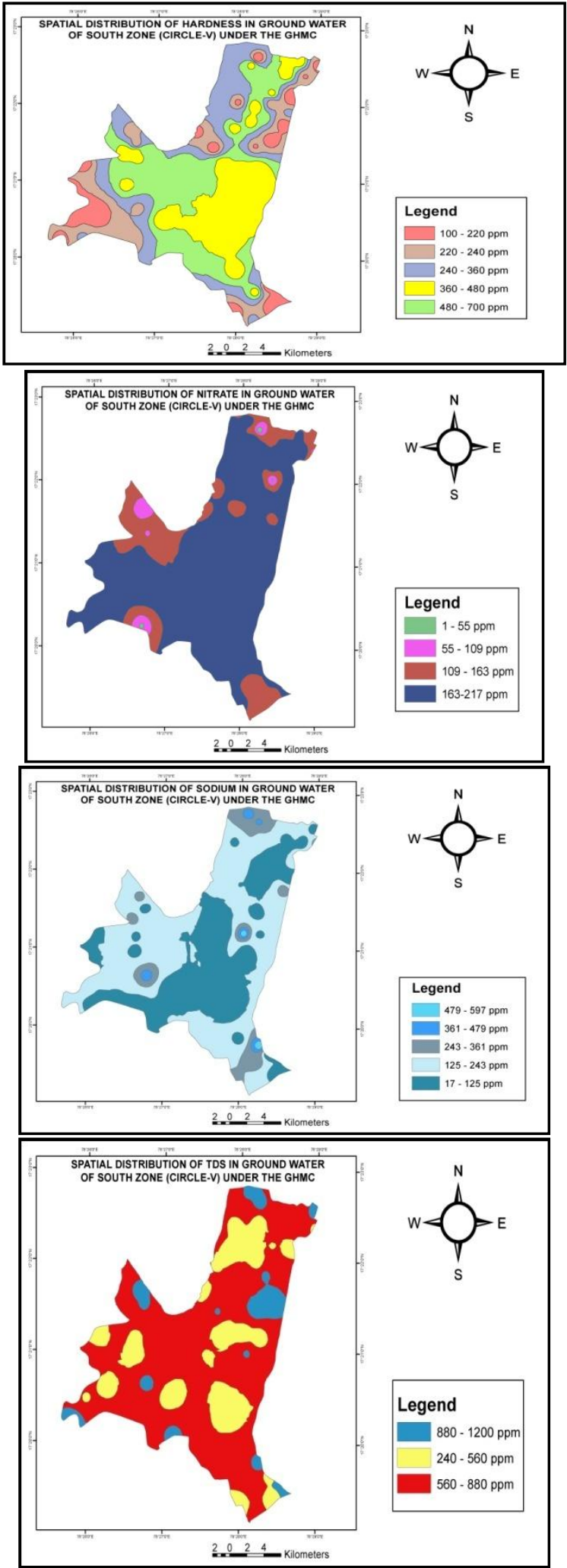

Fig -4.1: Effects of water quality parameters of Hardness, Sodium, Sulphate and TDS. 


\subsection{Remote Sensing and GIS}

Remote sensing Techniques are the science and art of obtaining information about an object, area or phenomenon through the analysis of data acquired by a device that is not in contact with object area, or phenomenon under investigation. Electromagnetic energy sensors that are currently being operated from airborne and space borne platforms to assist in inventorying, mapping and monitoring earth resources

With the aid of location, and condition of the various resources over which the senor data were collected. This information is then compiled generally in the forms of hardcopy maps and tables or as computer files that can be merged with other "layers" of information in a geographic information system (GIS) [5] [6]. The role that reference data play in the data analysis procedure and describe how the spatial location of reference data observed in the field is often determined using global positioning systems (GPS) methods.

\section{RESULTS AND DISCUSSIONS}

The below bar charts shows the results

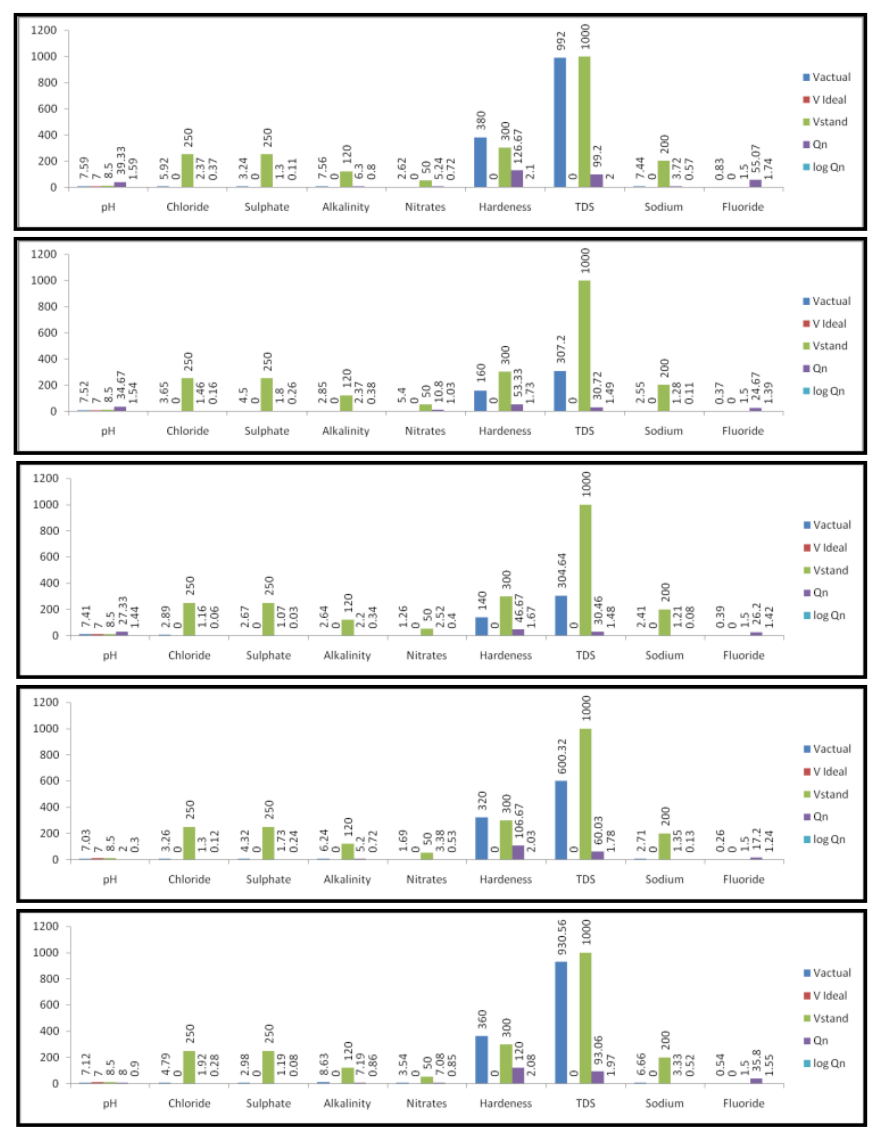

Fig -5.1: Effects of water quality parameters samples taken from the Hyderabad Zone - V areas.

\subsection{Discussions}

The water quality Index [1] can be a very special and efficient tool for communicating the information on overall quality of water, in present study the water quality rating in $\mathrm{MCH}$ Zone $\mathrm{V}$ varied from good, poor, very poor to unfit for human consumption. The water quality of a place may be related to land use in that area. The more land use more will be environmental degradation [1]. From the Land use / Land cover and water quality index obtained in the present study. It is observed that water quality deteriorated. Residential and commercial areas are reasonably good except Golnaka which showed high value of fluoride.

However water quality is poor in some residential and commercial areas like Narayanaguda, Begumbazar, Nimboliadda and in Amberpet where small-scale industries like flourmills and papermills are located Very poor water quality is found in dense residential areas like Police Academy, near L.B. Stadium, Bazarghat, Navbath Rahar etc, which may be due to seepage of domestic sewage. In areas like Golnaka, Zindathnagar, Koti, Hyderguda, Goshamahal, Imlibun, Sewerage treatment plant at Amberpet the WQI showed that the water is not fit for human consumption. This can be attributed to high concentrations of Fluoride, TDS, Nitrates and Alkalinity observed in the above areas. Fluoride and hardness showed a maximum concentration of $(5.83 \mathrm{mg} / 1$ and $710 \mathrm{mg} / 1)$ respectively at Golnaka. While highest values of TDS $(1180 \mathrm{mg} / 1)$ at Imlibun bus station, highest value of Alkalinity $(690 \mathrm{mg} / 1)$ at Kamalanagar, Nitrate of $140 \mathrm{mg} / 1$ near Bathkammakunta were observed. The possibility for the high concentration observed in the above parameters is contamination of ground water by domestic sewage and also due to the fact that sewage is directly discharged into Musi River, Stream of Musi River (Kamalanagar Musi) and, Bathkammakunta.

\section{CONCLUSIONS}

Based on the water quality data obtained from physicochemical analysis and WQI, the areas where ground water showed high concentrations of water quality parameters are identified. The results indicated that certain parameters such as fluoride, TDS, Hardness, Alkalinity, Nitrates exceeded the permissible limits as given by Bureau of Indian Standards. Concentrations of Sodium, Potassium, Sulfate, Chloride and Phosphate were observed to be within the permissible limits. The Recommendations are suggested based on source of pollutant and drinking water standards of the parameters and the associated Land use.

Remote sensing [4] and GIS [7] should be used in the sites where percolation tanks and rain water harvesting pits can be constructed which helps in recharging the ground water levels. Point sources of pollution like open nallahs, waste disposal sites should be identified and appropriate remedial measures like proper sewerage network and relocation of waste 
dumpsites must be undertaken. Relocation of certain activities in and around Musi River such as cattle washing, Dhobighats, and sporadic development of slums must be stopped. The study is mainly focused on the methodology, which derives a correlation between the landuse and environmental parameters. In the present study, this methodology has been worked out on a single zone. To get a comprehensive picture of the water quality of Hyderabad urban area (Zone V) similar studies have to be performed for the remaining zones. In the present study the features affecting the quality of both air and water are studied and based on the conclusions broad policies/recommendations are suggested for the consideration of development of Hyderabad urban area.

\section{REFERENCES}

[1]. Abdel-aziz Ismail Kashef, Ground Water Engineering, Me raw Hill International Editions 1986.

[2]. APHA, AWWA, WPCF. Standard Methods for the Examination of Water and Wastewater. 20th edition, American Public Health Association, Washington, DC, New York, USA, 1998.

[3]. Burligame, G.A., 1999. Odor profiling of environmental odors, Water Science and Technology, 6:31-38.

[4]. Ritchie, J.C., Schiebe, F.R and McHenry, J.R. (1976). Remote Sensing of Suspended Sediment in Surface Water. Photographic Engineering Remote Sensing, 42, 1539- 1545.

[5]. R.S. Suja Rose and N Krishnan (2009), "Spatial Analysis of Groundwater Potential using Remote Sensing and GIS in the Kanyakumari and Nambiyar Basins, India", Journal of the Indian Society of Remote Sens ing, 37(4), pp 681-692.

[6]. Ritchie, J.C., 2000. Soil Erosion, Remote Sensing in Hydrology and Water Management (G.A. Schultz and E.T. Engman, editors), Springer-Verlag, Berlin, Germany, pp. 271286, 349-350.

[7]. Saraf A.K. and Choudhury P.R., Integrated Remote Sensing and GIS for Groundwater Exploration and Identification of artificial recharge sites, Intl. J. Rem. Sen, 19(10), 1825-1841 (1998).

[8]. ZHONG, K. W., LIU, X. L., XIE, L. \& C. G. SUN (2009): Study on the Inversion Model of the Suspended Sediment Concentration at the Pear River Delta Based on Remote Sensing Technology. Remote Sensing Information (1): 49-59.

\section{BIOGRAPHIE:}

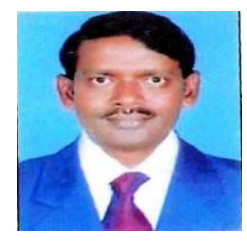

Gogana Venkateswarlu is presently a research scholar in the department of Civil \& Geo Engineering from Andhra University, Vishakapatnam, A.P, India. And working as an Associate professor in the department of Civil Engineering at Anurag Group of Institutions, JNTU Hyderabad. He has been achieved great honor like he has been awarded Bharat Jyothi Award in Science and Technology - December 2008, UGC- Junior Research Fellowship - March 2004, CSIR - Senior Research
Fellowship - April 2004, and he has got membership in Indian Science Congress Association Kolkata and Registered Architect in Council of Architect, New Delhi, India. 